\title{
DE BOUWGESCHIEDENIS VAN DE BURGERLIJKE GRIFFIE TE BRUGGE
}

Het elegante en zo karakteristieke bouwwerk dat ons op het burgplein opvalt door zijn schilderachtigheid is tot op heden zelden of niet van nabij bestudeerd geworden ${ }^{1}$. Het ligt in onze bedoeling hieraan te verhelpen door een grondig onderzoek in te stellen naar de oprichting en de evolutie van dit merkwaardig monument dat te Brugge één der weinige getuigen is van renaissancearchitectuur.

De huidige konstructie werd opgericht in vervanging van een ander gebouw dat lange tijd deel had uitgemaakt van het kasteel «de Loove» en dat in 1434 aan de stad werd afgestaan om er haar burgerlijke griffie te installeren. Omdat dit bouwwerk, dat wellicht zeer oud was, zulke tekenen van verval vertoonde besloot men het af te breken. Karel V in persoon gaf hiervoor zijn toestemming.

Deze eerste fase werd waarschijnlijk begin 1534 uitgevoerd. De stadsrekeningen verschaffen ons wat dat betreft geen waardevolle inlichtingen.

De eigenlijke opbouw verloopt in verschillende schijven. De financiële toestand was in die tijd immers niet zo schitterend.

Aan Christiaen Sixdeniers, die Jan de Maech als meestermetselaar van de stad had opgevolgd, werd opgedragen met het opgaande werk te beginnen ${ }^{2}$ «... ende maecken vanden maetswercke vanden voorbuyse vander greffe deser stede met eenen comptoire ofte camere over de straete tusschen den scepenbuyse deser stede ende den buuse ter greffe...».

1. Vermelden we evenwel het artikel van L. Gilliodts Van Severen, l'Ancien greffe de la ville de Bruges, in La Flandre, X, 1879, p. 425 e.v. Deze bijdrage is echter onvolledig en we ontdekten talrijke foutieve verwijzingen.

2. Stadsrekening 1534-35, fol. 66, nr 3: «Den voors. de somme van acht hondert guldenen van XL gr. tstick in minderinghe van XVII gelycke guldenen by hem bevoorwaert omme tleveren ende maecken vanden maetswercke vanden voorhuuse vander oreffe deser stede met eenen comptoire ofte camere over de straete tusschen den scepenhuuse deser stede ende den huuse ter greffe, naer tverclaers vander voorwaerde daerof zynde te betalene VIII ${ }^{\mathrm{c}}$ guldenen ghereedt, $\mathrm{II}^{\mathrm{c}}$ guldenen te Bamesse vivendertich ende de reste ghelt naer werck die hier over teerste ghereet payment de voorn. VIII ${ }^{c}$ guldenen». 
Wat de betekenis is van de hier gebruikte term «voorhuuse» weten we niet. Het blijkt in ieder geval om een gedeelte der werken te gaan waarbij men van plan was de volgende schijf later te ondernemen. Wellicht gaat het hier enkel om de gevelpartij.

Sixdeniers zal voor de opbouw 1.700 gulden krijgen, uit te betalen in drie schijven te weten: 800 gulden bij de aanvang van het werk, 200 gulden op het feest van St.-Bavo ( 1 oktober) en de rest na de voltooiing.

Deze meester-metselaar, hoe bedreven in zijn vak ook, werd evenwel niet angezocht om de plannen te vervaardigen. Hij fungeerde enkel als aannemer. De «architect» was een vreemdeling: Jan Wallot, steenkapper ${ }^{3}$.

Verschillende auteurs deden reeds opzoekingen naar de herkomst van deze man. Talrijke hypothesen werden vooropgezet maar geen enkele was doorslaggevend. Dit is voornamelijk te wijten aan het gebrekkige bewijsmateriaal waaruit men moet putten. Onze persoonlijke opzoekingen leverden evenmin een onweerlegbare oplossing voor het probleem op. Onze gedachtengang is bijgevolg ook hypothetisch en laat een nieuwe studie naar de oorsprong van genaamde Jan Wallot open.

Prof. D. Roggen meent Jan Wallot te kunnen vereenzelvigen met Jan Mone ${ }^{4}$. Deze laatste heeft de nieuwe vormgeving der Renaissance in onze gewesten verspreid. Omstreeks 1530 was hij vermoedelijk te Brugge, daar in de rekeningen van het Vrije van $1529-30$ een betaling voorkomt aan "meester Jan l'Artiste» ${ }^{5}$. Hij werd dus geraadpleegd en gaf wellicht aanwijzingen voor de esthetische vormgeving. In datzelfde jaar wordt hij in bedoelde rekeningen een tweede maal vermeld wanneer hij het stadsbestuur aanraadt Andries Monnon aan te zoeken voor het leveren van het zwarte marmer ${ }^{6}$. Jan Mone was in deze periode woonachtig te Mechelen en genoot groot aanzien als «artiste de l'Empereur».

3. Stadsrekening 1534-35, fol. 68 v., nr 4: «Jan Wallot, steenhauwere, over tmaecken van eenen patroone vanden werke omme tbesteden van tmaecken vanden huuse ter greffe deser stede by zyne quitantie XXIII s. IIII den.».

4. D. Roggen, Jeban Mone, Artiste de L'Empereur, in Gentse Bijdragen tot de Kunstgeschiedenis. XIV (1953), p. 228.

5. Zie tekst bij D. Roggen, o.c., p. 224.

6. Zie tekst bij D. Roggen, o.c., p. 224. 
Het is wel van belang, zo menen we, op te merken dar Jan Mone in bovengenoemde stukken steeds als «Jan Artiste» of «Jan Lartist» wordt beschreven.

Deze toevoeging van «l'Artiste» komt trouwens in de meeste stukken betreffende zijn persoon voor. Hij was immers in dienst van Karel V en in officiële stukken zal men zeker niet nagelaten hebben de kunstenaar als zodanig te vermelden. Hierom reeds durven we zeggen dat de Jan Wallot uit de rekeningen van 1534-35 niet Jan Mone is. Wanneer men een kunstenaar met zulk een faam als Mone had aangezocht om de plannen te tekenen voor een gebouw dat toch op de burgplaats moest worden opgetrokken dan zou men ons inziens zeker niet nagelaten hebben dit in de officiële stukken te vermelden.

Een tweede argument waarmee we de stelling van Prof. D. Roggen menen te mogen bestrijden is dit: Jan Mone kennen we enkel als beeldhouwer. De opdrachten die hem worden toevertrouwd betreffen bijna alle decoratief beeldhouwwerk. De genaamde Jan Wallot wordt uitdrukkelijk als «steenhouwere» omschreven, een betiteling die we nooit bij Mone aantroffen. Op dit tijdstip had de benaming «architecte» in onze gewesten zeker nog geen ingang gevonden. Het was regel de opdracht voor het tekenen van plannen toe te wijzen aan een «meester maetsenare» of een «steenhouwere». Het lijkt ons bijgevolg duidelijk dat het hier niet om Mone gaat maar om een vreemdeling waarover we verder geen nauwkeurige gegevens konden verzamelen. Wellicht is hij dezelfde als de "Jan Wallo steenhouwere» die in 1552 te Brugge werkzaam was ?

De financiële toestand was te Brugge op dat ogenblik niet zo rooskleurig dat men de beurs kon openen om «l'artiste de l'empereur» te betalen voor het ontwerpen van de plannen voor hun burgerlijke griffie.

Dat in de versiering van de gevel zekere kenmerken van de stijl van Jan Mone aanwezig zijn valt niet te loochenen. We zegden reeds dat hij bij ons de belangrijkste vertegenwoordiger van de nieuwe richting was. Hij zal dus veel epigonen gehad hebben die in min of meerdere mate zijn specifieke werkwijze copiëerden. Zijn invloed is dus mogelijk maar niet onbetwistbaar zeker. We menen met Prof.

7. Zie D. Roggen, o.c., p. 224-225. 
J. Duverger dat Mone «... Niet de eerste, noch de eenige is, die de kunstrichting vertegenwoordigt...» ${ }^{8}$.

Dat het niet gewettigd is de hand van Mone te zien in de opbouw en de structuur van de gevel zelf is naar ons gevoel overduidelijk. Het geraamte is nog zuiver gotisch en de bekroning door drie puntgevels sluit daar direct bij aan.

Zo Mone, zó vertrouwd met en onderlegd in de vormgeving naar Italiaanse normen, rechtstreeks bij de opbouw betrokken was geweest, dan had hij ook de structuur in die zin omgevormd. Dat men integendeel inspiratie is gaan zoeken bij reeds bestaande voorbeelden (b.v. woonhuis Vlamingstraat 11, Brugge) pleit nog meer voor onze hypothese.

We menen derhalve dat men hier op een dwaalspoor zit en in een andere richting dient gezocht. We behouden ons een nieuwe studie naar de herkomst van deze Jan Wallot voor.

Ondertussen kenden de werken enige vertraging door allerhande faktoren:

1) de uitbater van de groeve waar de te gebruiken steen vandaan moest komen, Liévin van Male, was te laat met het leveren van de blokken. Er werd zelfs een proces aanhangig gemaakt en het was Joos de Boodt die hierbij de belangen van de stad moest verdedigen ${ }^{\text {. }}$.

2 ) het oorspronkelijke opzet werd gewijzigd ${ }^{10}$.

3) tegenstand kwam er ook vanwege de instelling van het

8. J. Duverger, Conrat Meyt, Gent, 1934, p. 62-63.

9. Stadsrekening 1535-36, fol. 65, nr 1: «Den selven Meester Joos XXV scellinghen grootten van dat hy by laste ende ordonnancie vanden college reysde binder stede van Ghendt, omme aldaer te betreckene in justicien ende upte roupene Meester Lievin van Male, steenhauwer, voor die van der wet der zelver stede, omme hem bedwonghen 'thebbene ter leveringhe van den steene dienende omme 'tmaecken van der greffe civil deser stede, daerinne hy vachierde V daghen, te wetenen: van den XXen totten XXVen van der voornoemde maent van meye ten $\mathrm{V}$ scellinghen grooten sdaechs».

10. Secrete Resolutiën van de Stad Brugge, 1535-36, fol. 35 v., nr 2: 22 maart 1535 vóór Pasen: «Ten zelven daghe was gheresolveert of te brekene de zyetmuer vanden huuse vande greffe commende in de Blende Ezelestraetken vanden zyde van der oude sale tot de eetcamere, ende die van ouders nieuwe up te makene ende met ordune steenen totter eester staige ende de reste te rycken, ende was ghelast bede tresoriers 'tzelve werck te bestedene ten meesten prouffyte deser stede, zonder nochtans mr. Christiaen Sydeniers eenighen langheren dach te consenteren noopende zijn eerste aanghenomen werck dan hem by voorwarde gheconsenteert es gheweest». 
Vrije die beweerde als zou de fundering van de griffie op die van het «Loove» staan ${ }^{11}$.

Hierbij werd evenwel overeengekomen dat de werken konden voortgezet worden. De delegatie van het Vrije laat het verder bebouwen op haar grondgebied toe indien de stad haar geen nadeel berokkent. Dit wordt vastgelegd en goedgekeurd, doch de stad eist tevens dat ze het bewijsstuk zou te zien krijgen waaruit blijkt dat het Vrije wel degelijk deze grond eerder bezat dan de stads oude vierschare bestond en of bijgevolg haar rechten juist zijn.

Hoewel de afgevaardigden dit beloofden lezen we op datum van 5 april 1536 dat aan deze wens nog steeds niet was voldaan. Het stadsbestuur stelt nu zelf paal en perk aan het bouwland, geen rekening houdend met de mogelijkheid dat het Vrije dit stuk eerder bezat ${ }^{12}$.

Het is dus niet verwonderlijk dat de werken enige ver-

11. Secrete Resolutiën van de Stad Brugge, 1535-36, fol. 38, nr 1, 31 maart 1535 vóór Pasen: «Ten zelven daghe compareerden voor 't college joncheere Jacop de Voocht, Adriaen Louis, scepenen vanden Vrijen, en $\mathrm{mr}$. Jooris Horenboult, pensionaris vanden Landen vanden Vrijen, vertooghende dat die vanden Vrijen naer diversche ramynghen ghehouden up 't versouck ende vertooch hemlieden ghedaen by die van Brugghe, noopende zekere fundementen ende pilaeren ghemaect an de greffe deser stede omtrent heurlieder galerye, up heurlieder erfve, omme die van Brugghe te ghelievene waren te vreden den zelven van Brugghe te consenteeren voort te gaene met heurlieder werck, hebbende van die van Brugghe lettren van nonprejudicie naer 't uutwysen van zekere minute die zy exhibeerden, daer inne die van Brugghe met zekere veranderinghe daerinne ghedaen consenteerden ende bedancten den zelven vanden Vrijen van heurlieder goetwillicheyt, behoudens nochtans dat zy alvoorens begheerden te zien de lettren die zy hebben van dat de erfve vande voorseide plaetse hemlieden verdere toebehoorde dan heurlieder oude vierschare ghestaen heeft van 't welcke zy last namen den college te adverteeren».

12. Secrete Resolutiën van de Stad Brugge, 1535-36, fol. 38 v., nr 4, 5 april 1535 vóór Pasen: «Was gheresolveert by den college dat men die vanden Vrijen gheven ende leveren zoude de lettren van consente ende van non-prejudicie, naar 't uutwysen vande minute by hemlieden up den laetsten dach van maerte overghebrocht metter ampliatie daertoe ghevoucht in meerdere versekerthede van elcken daertoe voughende, ende adjousterende dat de plaetse daer heurlieder oude vierschare up ghestaen heeft, ende die zy weder zoude meughen betemmeren, lanck es vichtien voeten, beghinnende vande galerie diere nu staet ende hendende an de zydtmeur vander greffe, al eyst ooc zoo dat die vanden Vrijen van gheenen advyse en waeren die van Brugghe te tooghene de briefven van erfvachtichede ende proprieteyt, die zy verclaerst hebben daerof hebbende». 
traging kenden. Niettemin is de stad toch zeer streng. Op 19 mei 1536 laat ze Christiaan Sixdeniers weten dat ze niet langer enige vertraging kan dulden en dat hij zeker de in het bestek voorziene uitvoeringstermijn niet mag overschrijden. Hierin stond beschreven dat de werken moesten beeindigd zijn tegen eind augustus $1536^{13}$. Zo hij binnen deze tijdslimiet niet klaar kwam zouden hem honderd gulden van zijn wedde afgetrokken worden.

De maatregelen konden echter niet baten. Op 2 september moet Sixdeniers zich voor de stadsregering verantwoorden: hij voert aan dat hij niet kon vorderen omdat de steen niet bijtijds werd aangevoerd. Ondanks dit geldige excuus veroordeelt het college hem tot honderd gulden boete ${ }^{14}$.

Op dezelfde zitting worden de andere bijkomende werken toegewezen. Aan Liefaart vander Biest, meester timmerman, wordt al het timmerwerk toegewezen. Het contract wordt even nadien gesloten ${ }^{15}$.

13. Secrete Resolutiën van de Stad Brugge, 1535-36, fol. 45 v., $\mathrm{nr}$ 2, 19 mei 1536: «Was ghelast mr. Christiaen Sixdeniers met alder diligentie te vervolghene dat hy leverynghe ghecryghe vande steenen die hem behouden omme 't muurken vande greffe ende de Braemberchbrugghe deser stede, hem waerschuwende dat 't collegie van gheenen advyse was hem te renunchieren ofte quyte te scheldene de boete by hem te verburen ende die hy noch apparent es te verburen by ghebrecke van 'tvulcommen van zynder voorwaerde, ende nietmin 't zynen neersten versoucke was by den college ghedeputeert $\mathrm{mr}$. Joos de Boodt, omme met hem te reysene te Ghendt uuter naeme van den college, ende hem aldaer te assisteerne alzowel by die vande wet indien 't noodt wordt als anderssins».

14. Secrete Resolutiën van de Stad Brugge, 1535-36, fol. 61 v., nr 4, 2 september 1536: «Ten zelven daghe was mr. Christiaen Syxdeniers, ten versoucke vande tresoriers deser stede, ghehoort zyne kenesse ende excuse ende ghezien de voorwaerde ' $t$ anderen tyden ghemaect tusschen hem ende de tresoriers deser stede noopende't maecken ende vulmaecken vander greffe deser stede, omme dieswille dat hy deselve greffe niet vulupghemaect en heeft binnen de maendt van ougst laetsleden, metsgaders ooc omme dieswille dat hy in de maendt van ougst in ' $t$ jaer voorleden alle 't hardsteen hier binnen der stede niet ghebrocht en hadde al naer 't uutwysen vander zelver voorwaerde, ghecondemneert ten prouffyte vander zelver stede de somme van hondert Carolus guldenen ende bovendien waren de tresoriers der zelver stede ghestelt onverlet omme in tyden ende wylen up hem te verhalene alle costen, scaden ende interesten die de voorseide stede ghedoocht ende gheleden heeft ende noch zal moeten lyden ende dooghen van ghebrecke vande vulcomminghe vander zelver voorwaerde».

15. Ferieboecken der Stedelijke Schatmeesters, 1526-41, fol. 93, nr 1. 
Ook deze ambachtsman kan niet op de voorziene datum (12 april) met het werk beginnen om de eenvoudige reden dat het metselwerk nog niet ver genoeg gevorderd was. Omdat hij ondertussen reeds veel schade had geleden werden hem de $96 \mathrm{lb}$. gr. vooraf betaald ${ }^{16}$.

Op 16 augustus 1536 wordt in de stadsregering beslist dat Simoen de schilder 20 s. gr. zal ontvangen voor patronen die hij maakte voor de beelden die de gevel zullen bekronen ${ }^{17}$. Hierbij wordt nergens gewag gemaakt van de voorstelling van deze beelden. Mogen we de auteurs geloven die beweren dat het gaat om de beelden van Mozes en Aaron en allegorische voorstellingen van de vier hoofddeugden ? Waar zij hun bronnen vandaan hebben weten we niet. Wij vonden er althans geen schriftelijke bevestiging van.

Tijdens de jaren 1536-37 wordt de gevel volledig afgewerkt. Christiaen Sixdeniers wordt verder afbetaald en hij krijgt nog $28 \mathrm{lb}$. gr. extra omdat hij het oorspronkelijke ontwerp uitgebreid had «... 't voornbuus $X X$ voeten langhere te makenen dan de eerste voorwaerde.... ${ }^{18}$.

Wellicht wordt hier de gevel bedoeld. Hij had tevens de kelders overwelfd en een trap gebouwd ${ }^{19}$.

16. Stadsrekening 1535-36, fol. 71 v., nr 3: «Lyfaert vander Biest, themmerman, de somme van IIIIxxXVI lb. X s. gr. over ghelycke somme by hem bevoorwaert omme tleveren ende maecken vanden houtewercke vanden huuse ter greffe civil deser stede, volghende der voorwaerde ende bestedinghe daerof ghedaen, te betaelene een derde ghereet, een ander als twerck ghereet es ende de reste ten vulmakene vanden wercke. Dus hier hoewel twerck niet gherecht en es dat bij zynen schulden niet en es de voors. IIIIxxXVI lb. X s.».

17. Secrete Resolutiën van de Stad Brugge, 1535-36, fol. 57 v., nr 2, 16 augustus 1536: «Was by den college my ghelast over te commene met $\mathrm{mr}$. Simoen de scildere, woonende up St.-Jansplaetse, noopende zynen loon van de patroonen vande beelden ende personaigen die up de greffe civille staen zullen, by hem ghemaect, ende hem daeraf consenteeren totter somme van XX s. gr. end daer ondere, ende was den tresorier ghelast dezelve te betalene zulcke somme als daermede ic hem zal connen tevreden stellen tot de voors. somme van $\mathrm{XX}$ s. gr. ende daer ondere». (In margine): Dezelve es tsydert gheconsenteert gheweest met XVI s. VIII d. gr.

18. Stadsrekening 1536-37, fol. 69, nr 1: «Alvooren Christiaen Syxdeniers, Mr. maetsenare, deser stede de somme van LX lb. gr. als reste, ende over de vulle betalinghe van $\mathrm{XVII}^{c}$ gulden by hem bevoorwaert omme tleveren ende maecken vanden maetswercke vanden voorhuuse vander greffe deser stede volohende der voorwaerde ende den voorgaende rekenynghen, dus hier by zyne quictancie de voorn. LX lb. gr.».

19. Stadsrekening $1536-37$, fol. $69, \mathrm{nr} 2$ : «Den voors. de somme 
Aan de verdere afwerking werkten mee: Adriaan de Vos, herkomstig uit Dordrecht, voor de leibedekking; Jacob de Witte, schipper, levert de schaliën en 1.700 «duughen» uit de Rijnstreek ${ }^{20}$; Antoon van Lombrouck, meester timmerman, levert deuren en vensterramen ${ }^{21}$.

De patronen door schilder Simoen Pieters vervaardigd werden uitgevoerd door Willem Aerts, steenhouwer ${ }^{22}$. Het is duidelijk dat de beelden die de toppen der gevel bekroonden in steen werden gekapt.

Op 16 februari 1537 besluit het schepencollege de hogergenoemde beelden; zowel als de gehele gevel te laten po-

van XXVIII lb. gr. als reste ende over de vulle betalinghe van LVIII lb. gr. by hem bevoorwaert van voorn. huus $X X$ voeten langher te makene dan de eerste voorwaerde, metgaders onder tgheheele huus een vaulte te makene ende de stoffe daertoe te leverne, volghende der zelver voorwaerde ende der voorgaende rekenynghe dus hier de zelve XXVIII lb.». - nr 3: «Den zelver ter causen van tleveren ende maecken van eenen wentelsteeghere van ordune inde plaetse vanden voorn. huuse, dienende ten zelven huuse van onder tot boven inde opperste staige by voorwaerde met hem daerop ghemaect ende zyne quictancie de somme van XXXIII lb. VI s. VIII d.».

Randnota: «by affirmatie van burchmeesters, scepenen ende tresoriers, metgaeders de bewysen inde text ghementionneert ende andere bewijsen ghenoteert up de marge, behoudens mietmin de lasten hier achter».

20. Stadsrekening 1536-37, fol. 71 v., nr 1: «Jacop de Witte, cuupere, vuer de leveringhe van XVII rynsche duughen by hem ghelevert ende verbesicht int decken vanden huuse ter greffe met scaillen..». - Stadsrekening 1535-36, fol. 72 v., nr 1: «Adriaen de Vos, scippere van Dordrecht, over den coop ende leveringhe van XXXcc scaillen te Dordrecht ghecocht ten XIX s. VI d. gr. tduust, XXIX lb. V s. gr., over den tol te Dordrecht V lb. gr., van thallen vanden zelven scaillen V s. gr., vuer den tol terminde II gr. ende II lb. XIII s. gr., vuer de vrecht van daer tot binnen deser stede ghecocht, omme tdecken vanden huuse ter greffe deser stede bedraghende tsamen de voornoemde partien ter somme van XXXII lb. XIX s. II d. gr.».

21. Stadsrekening 1536-37, fol. $71, \mathrm{nr} 1$ : «Anthuenis van Lambrouck, meester themmerman deser stede, van tleveren ende maken vande zolders, cassynen, dueren ende veynsters vande huuse ter greffe upden burch deser stede, volghende der voorwaerde ende bestedinghe daerof ghedaen LXIII lb. XVI s. gr. - Den zelven van voorn. werck te ghelde te stellene blyckende byder zelver voorwaerde ende zyne quictancie, de somme van XXVI s. VIII d. gr. bedraghende tsamen de voorn. partien ter somme van LXV lb. II s. VIII d. gr.».

22. Stadsrekening 1536-37, fol. 69, nr 5: «Willem Aerts, steenhauwere, van dat hy de ymaigen, staende upden ghevele vander greffe, meerder ghemaect heift dan de voorwaerde naer dat hij eenighe ghemaect hadde by laste vander tresorie ende zyne quictancie III lb. gr.». 
lychromeren ${ }^{23}$. Het is Jan Zutterman die het werk uitvoert voor $32 \mathrm{lb}$. gr. ${ }^{24}$.

We kunnen hieruit dus besluiten dat het gebouw volledig was afgewerkt. Dat alle moeilijkheden hiermee van de baan waren is evenwel overdreven.

Immers op 12 juli 1537 verschijnen voor het schepencollege van de stad Brugge, de burgemeester van het Vrije, Jan de Cherf en zijn raadslid Noël Caron om klacht neer te leggen voor het feit als zou in de muur toebehorend aan het Vrije twee stenen zijn gemetseld als steun voor de balken die dienden om een klein bureautje te installeren boven de keuken van de griffie ${ }^{25}$. Ze eisen een bekentenisbrief en schadevergoeding. Ditmaal moet het stadsbestuur de duimen leggen. Op 21 augustus ondertekent het een schadevergoedingsakte ${ }^{26}$. Toen reeds zorgde naijver voor dergelijk politiek gekibbel !

We hebben de stadsrekeningen verder onderzocht om na te gaan of het gebouwtje in de daaropvolgende eeuwen tot zijn restauratie in 1877 aan noemenswaardige verbouwingen of andere wijzigingen onderworpen werd.

In het jaar 1551 wordt de griffie hersteld. Jooris Wittebroot «meester matsenare» wordt hiervoor aangesteld en betaald ${ }^{27}$. Waarop die reparaties betrekking hebben weten we echter niet.

23. Secrete Resolutiën van de Stad Brugge, 1536-37, fol. 27 v., $\mathrm{nr} 2,16$ februari 1536 (1537): «Was gheresolveert dat men de beilden die staen zullen up de nieuwe greffe deser stede zal stoffeeren ende scilderen, metgaders ooc de ghevele naer den heesch vanden wercke midts dat die vande tresorie den college te kennen ghegheven hebben dat ' $t$ zelve maer costen en zal omtrent $\mathrm{II}^{\mathrm{C}}$ Carolus guldenen, daerinne begrepen de beelde van wylent coninck Philips, salegher memorie, staende voor t' scepenhuys».

24. Stadsrekening 1536-37, fol. 71 v., nr 5: «Jan Zutterman, schildere, van gheschildert ende ghelootwit thebbene de voorghevele ende ymaigen vanden huuse vander greffe deser stede metter ymaige vanden conync Phelipe van Castillen, staende voort scepenen huus... met syne quictancie de somme van XXXII lb. gr.». - Stadsrekening 1537-38, fol. 68, nr 3: Jan Zutterman, schildere, van eenighe partien van schilderien by hem voor de stede ghedaen, binden tyde van deser rekenynghe metten overwercke ghedaen, anden ghevele ende huus ter greffe by eene rekenynghe ende twee zyne quictancien $\mathrm{V}$ lb. VI s.».

25. Secrete Resolutiën der Stad Brugge, fol. 63, nr 2.

26. Procuratiën 1536-37, fol. 164.

27. Stadsrekening 1550-51, fol. 74 v., nr 1: «Alvooren Jooris Wittebroot, meester matsenare deser stede, van zekere wercken ende 
Jan Boone «Scailledeckere» moet in 1552 het dak vernieuwen ${ }^{28}$. Aan de gevel zelf wordt in de komende decennia niet meer geraakt.

In 1568 wordt de binneninrichting vernieuwd. Vader en zoon Van Eecke maken nieuwe toonbanken ${ }^{29}$.

Martin Boone, timmerman, moet in 1570 «een hanghende camerkin» maken voor de griffie ${ }^{30}$.

In 1571 moet dezelfde verder het binnenwerk van «de camere» herstellen ${ }^{31}$. Voor deze reparaties krijgt hij ook in 1572-73-74 geld ${ }^{32}$. Andere «refectien» worden door Martin Boone «doude» uitgevoerd in 1575, daarvoor ontvangt hij 72 lb. 11 s. 5 gr. ${ }^{33}$.

Cornelis Tulpin doet «diversche cleene wercken» in het jaar 1581. Het betreft hier hoogstwaarschijnlijk weer het interieur ${ }^{34}$.

Pas in de stadsrekening van 1607 vinden we een volgen-

reparracien by hem ghedaen binnen deser jaerschare an diverssche edificien als vanden greffe, upde vanghenesse, an tnieugherechte ende diverssche cayen ende steeghers, ende elders al naer tuutwysen van twee zyne rekeninghen, onderteekent by scenenen, de somme van XXXVIII lb. XVII s. gr.».

28. Stadsrekening 1551-52, fol. 66, nr 2: «Jan Boone, scaeilledeckere, van zekere wercke ende leveringhe van stoffe by hem ghedaen ende ghelevert, tzynen ambachte aengaende, an diverssche daecken als vander greffe ande lanteerne vande oude halle... XX lb. XII s. IX d. $1 / 2$ gr.».

29. Stadsrekening 1567-68, fol. 73 v., nr 1: «Lucas van Eecke, vadre ende zone, temmerlieden, van zekre comptoiren ghemaect thebbene inde greffie deser stede, volghende de rekenninghe danof zynde onderteekent byden greffier V lb. XIIII s. V gr.».

30. Stadsrekening 1569-70, fol. 64, nr 3: «Martin Boone voor tmaken ende leveren van een hanghende camerkin inde greffie civile deser stede, by ordonnantie, XVI lb. gr.».

31. Stadsrekening 1570-71, fol. 63, nr 5: «Martin Boone, ooc temmerman, van reparatien by hem ghedaen ande comptoiren ende cameren inde greffie civile X $\mathrm{lb}$. IX $\mathrm{s}$. gr.».

32. Stadsrekening 1571-72, fol. 57 v., $\mathrm{nr}$ 3: «Martin Boone, ooc temmerman, van wercken ende reparatien by hem ghedaen inde greffie civile, by ordonnantie ende quictantie, VIII lb. gr.». - Stadsrekening 1572-73, fol. 63 v., nr 3: "Martin Boone, doude, van wercken ende reparatien by hem ghedaen inde greffie civile... IIII lb. XI s. VI gr.». - Stadsrekening 1573-74, fol. 55 v., nr 3: «Den zelven Martin Boone, doude, van diverssche refectien by hem ghedaen in de greffie civile II lb. XI s. VI gr.».

33. Stadsrekening $1574-75$, fol. 57 v., $\mathrm{nr} 1$.

34. Stadsrekening 1581-82, fol. 40, nr 4: «Cornelis Tulpin over dyverssche cleene wercken by hem ter greffie civil met leveringhe vanden houtte II lb. gr.». 
de vermelding. Joos van Troostenberghe, smid, vernieuwt de sloten der ramen en de afvoerpijpen ${ }^{35}$.

Wellicht wordt in 1608 aan de gevel gewerkt want Jan en Ferry Aerts leveren blauwsteen. Nadere gegevens ontbreken ook hier ${ }^{36}$.

In de vijftiger jaren wordt weeral aan de inrichting gewerkt. Gillis Moerman giet lood om een «pompe» te herstellen ${ }^{37}$.

Pieter Ely moet in het jaar 1743 vijfendertig ramen «verlooden». Het ging hier wellicht om het vernieuwen van alle vensters der griffie ${ }^{38}$.

In 1752 tenslotte vonden we nog een vermelding van dakherstellingen door Jan van Ockerhout, meester loodgieter ${ }^{39}$.

Uit wat voorafgaat kunnen we besluiten dat de griffie na zijn opbouw geen ingrijpende wijzigingen meer heeft ondergaan. Aan het monumentale gedeelte werd nooit geraakt zodat het gebouwtje ongeschonden de tijd trotseerde.

De restaurateurs uit de XIXe eeuw hadden nochtans met enkele zware problemen te kampen ${ }^{40}$. Dit was hoofdzakelijk

35. Stadsrekening 1607-08, fol. 34, nr 4: «Joos van Troostenberghe, smit ende slotmakere, van het beslaen ende vermaken van cassynen tot scepencamere ende greffie civile, metsgaders pypegalen ende diverssche andere wercken van zyne style, by een rekeninghe CI lb. XIIII s. III d. gr.».

36. Stadsrekening 1608-09, fol. 34 v., nr 4: «Jan ende Ferry Aerts van leverynghe van orduyn ende handwercq ande greffie civile ende ander stadswercken, by een rekenynghe CIIII $\mathrm{lb}$. XVIII s. IIII $\mathrm{d}$. gr.».

37. Stadsrekening 1652-53, fol. 98 v., nr 3: «An Heyndryck Schoenmaecker metten synen over 'tplacken van een camere inde greffie, by ordonnantie ende quictantie, de somme van II lb. XIIII s. gr.»; fol. $98 \mathrm{v} ., \mathrm{nr}$ 6: «An Gillis Moerman, gheluweghietere, over tghieten ende maecken van een metale hooft omme ande pompe inde greffie civile, by ordonnantie ende quictantie de somme van III lb. gr.».

38. Stadsrekening 1742-43, fol. 57 v., nt 2: «Aen Pieter Ely, meester glaesemaecker, alsvooren over het verlooden van 35 glaeseveinsters inde greffie vande camere als anders, by specificatie van de 24 juny 1743 , ordonnantie ende quictantie de somme van VI lb. $\mathrm{XV}$ s. gr.».

39. Stadsrekening 1752 , fol. $57, \mathrm{nr} 4$ : «Aen Jan van Ockerhout, meester lootgieter, alsvooren over eenighe reparatie ghedaen aent schaillie dack vande greffie vande camere ende het souderen van een loode gote met de leveringhe van schaillien ende naeghels by specificatie vanden 2 ougst, ordonnantie ende quictantie I lb. VIII s. VI gr.». 
het gevolg van het feit dat belangrijke decoratieve elementen totaal verdwenen waren. Bij ons rees onmiddellijk de vraag wanneer deze wijzigingen mochten gebeurd zijn. Het antwoord is nogal voor de hand liggend. De woeste vernietigingsdrang in 1792 had de ornamenten volkomen verbrijzeld zodat de eens zó rijkelijk versierde gevel een eerder troosteloze aanblik bood toen de rage voorbij was. Een en ander werd opgeknapt in het jaar 1797 zoals het besluit der gemeenteraad van 24 mei laat vermoeden ${ }^{41}$.

De algemene conceptie van de gevel, het compositorisch schema was evenwel behouden gebleven, zodat we ook nu nog een getrouw beeld hebben van wat het opzet was der constructeurs uit de XVIe eeuw, en wat het uiteindelijk resultaat is geworden.

Het valt ons in dit relaas op dat uitzonderlijk veel zorg werd besteed aan het «voorkomen» van een constructie die tenslotte niet van zulkdanig belang was.

Het is onze hoop dat dit markant en tevens monumentaal aandoend gebouwtje op de burg met zorg wordt bewaard voor een nieuwe toekomst.

K. WITTEVRONGEL

40. K. Norro, De restauratie van de Burgerlijke Griffie te Brugge 1877-1883, in Gentse bijdragen tot de kunstgeschiedenis en de oudbeidkunde, XXII, 1969-1972, p. 91.

41. «Vu le rapport du premier bureau consernant diverses réparations qu'il conviendrait de faire dans la comune; vu le devis estimatif du citoyen J. Devos, directeur des ouvrages communaux; portant les dites réparations à six cent dix huit florins douze sols argent courant; Considérant que ces réparations sont trop urgentes pour pouvoir les différer encore sans risque d'en occasionner de beaucoup plus conséquentes. l'Administrateur faisant les fonctions de commisaire du directoire exécutif entendu; Autorise son premier bureau à faire procéder de suite et le plus économiquement possible aux réparations susmentionées». Besluiten der Gemeenteraad, $24 \mathrm{e}$ mei $5 \mathrm{e}$ republikeins jaar (1797), fol. 186 v. en fol. 187 onder titel «Batiments Communaux». 